\title{
“被高铁”现象的理性分析 以京沪高铁为例
}

\author{
张凯烊, 孟晓晨* \\ (北京大学城市与环境学院,北京 100871)
}

\begin{abstract}
摘 要: 近年来, 中国高铁步人快速建设期, 而高铁建设的重要目的之一就是客货分流。高铁客运专线的建设大大 地提升了客运能力, 从而可以释放既有线路的运输能力于货物运输。但是高铁客运的票价也高于既有线路, 同时 由于普通列车车次的减少, 使得居民出行可能要被迫选择票价更高的高铁, 这种现象称作 “被高铁”。本文对媒体 关注的“被高铁”现象进行了理性分析, 以京沪高铁沿线城市为例, 根据 2015 年 1 月 1 日列车时刻表数据计算出的 时间节省的货币成本与小时工资(时间价值)作比较, 并结合高铁车次比重, 计算了不同城市的居民 “被高铁”的可 能性。研究发现: 1 很多“城市对”之间都存在时间节省的货币成本高于小时工资的情况, “被高铁”现象较为普遍; (2) “被高铁”的可能性在 50\%左右; (3)各城市“被高铁”的程度有较大差异, 京沪高铁沿线城市的“被高铁程度”整体 呈现出 “两头低, 中段高, 长三角相对较低” 的特征。研究认为, 虽然从目前来看, 京沪高铁沿线城市的普通列车班 次减少不明显, 但如果进行较大幅度调整, 很多低收人旅客出行时可能会被迫选择高铁, 并将带来负面的社会影 响。本文的理性分析可为列车班次的调整方案提供参考。
\end{abstract}

关 键 词: “被高铁”; 时间价值; 小时工资; 京沪高铁

\section{1 引言}

根据《中长期铁路网规划 (2008 年调整)》, 到 2020 年, 全国的铁路营业里程将达 12 万 $\mathrm{km}$ 以上, 主要繁忙干线要实现客货分线, 加强各大经济区之 间的连接, 在经济发达的人口稠密地区发展城际快 速客运系统。由于高铁速度快、客运量大, 高铁的 开通给客运带来的首要影响就是客源分流, 释放既 有线路的运输能力, 进而增加铁路的货运能力。截 至 2014 年底,全国高速铁路运营里程达 1.6 万 $\mathrm{km}$ 。 客货分线是高铁快速建设的必然结果, 中国高铁客 运专线的建设对于提高运输效率和客货运输服务 质量意义重大(海晓伟, 2014)。

高铁的建设不仅起到提升运输能力、改善城市 可达性的作用, 而且其快速、准时的特点也为旅客 的出行带来了便利。然而, 由于高铁相比普通铁路
具有更高的建设成本和运输成本, 因此其票价也相 应更高。高速铁路的建设成本主要包括基建成本、 技术成本、安全成本和环境成本(褚楠楠, 2013)。此 外, 由于固定资产折旧费和资本成本在运输总成本 中比例大, 有关设备的维修费用也较高, 再加上高 铁运行的能耗, 都进一步推动了高铁车票的高价格 (马崇岩, 2014)。高速铁路的高票价使得很多旅客 难以接受。对于收人不高的旅客群体, 他们若选择 铁路出行, 可能会被迫选择高票价的高速铁路, 这 种现象称为“被高铁”现象。低收人群体对出行时 间的长短没有太高要求, 而对交通费用的支出变化 更为敏感。比如北京一上海区间的直达普通列车 只有 T109和 1461 , 对于往返京沪间工资较低的旅 客,很有可能要支付更高的费用去购买车票。

“被高铁”现象最早在 2009 年 12 月底引起关 注。在武广高铁正式投人运营的前两天(2009年 12

收稿日期: 2015-10; 修订日期: 2016-02。

基金项目: 国家自然科学基金项目(41171131) [Foundation: National Natural Science Foundation of China, No.41171131]。 作者简介: 张凯烊(1991-), 男, 河南周口人, 硕士研究生, 主要从事城市经济与经济地理研究, E-mail: zky1991@126.com。 通讯作者:孟晓晨(1955-), 女, 黑龙江哈尔滨人, 副教授, 博士, 主要从事城市经济与经济地理研究, E-mail: xcm@urban.pku.edu.cn。 
月 23 日), 《经济参考报》的一篇文章称 “高铁的高票 价令公众失望”, 由此“被高铁”一词开始出现在新 闻中。其后, 媒体对 “被高铁” 的报道频率还较高地 出现在 2010 年 7 月 1 日沪宁高铁开通后、2011年 6 月 30 日京沪高铁的开通后, 以及 2011 年 12 月京广 高铁的正式运营后, 但总体上对这一问题的理性分 析还很缺乏。

“被高铁”现象之所以受到关注, 其原因可归为 以下几个方面: 一是车次因素。高铁开通后, 列车 运行图也相应地进行了调整, 减少了普遍列车的车 次, 这使得旅客出行有更大可能选择票价更高的高 铁。二是经济因素, 表现为高铁的高票价。以北京 到上海为例, 高铁运行约 $5.5 \mathrm{~h}$, 其中二等座 553 元, 一等座 933 元; 而 $\mathrm{D}$ 字头动车列车运行约 $12 \mathrm{~h}$, 二等 座309元。相比之下, 其他类型的列车则便宜了很 多, 如 $\mathrm{T} 109$ 次列车运行 $15 \mathrm{~h}$, 硬座 177 元, 硬卧 304.5 元; 1461 次列车运行 $20 \mathrm{~h}$, 硬座 156.5 元, 硬卧 283.5 元。三是中国铁路的准公共产品属性。表现 为中国的普通铁路的客运基准票价率一直沿用的 都是于 1995 年调整的为 5.861 分的客运基准票价率 (杨维凤等, 2009)。在高铁开通后, 其票价的高企与 铁路的准公共产品属性形成了对比。四是心理因 素。低收人旅客对于高铁的高票价一时难以接受。

目前对高铁的研究多集中于其正面影响。一 般来说, 高铁通过缩短旅行时间, 提高发车频次, 降 低了城市间人员流动的时间成本。同时, 高铁的建 设释放了原有铁路线路的货运能力, 从而促进城市 的经济发展。如 Monzón等(2013)通过研究高铁对 城市效率和空间平等的分析, 认为高铁可以提升城 市效率, 而不同的城市从高铁建设中获益不同。张 萌萌等(2014)基于铁路客运可达性的分析, 研究了 高速铁路对中国城市市场潜力的影响, 认为高铁的 建设不同程度地增强了沿海三大城镇群以及京广 与京沪两条廊道在未来的发展潜力。

“被高铁”有可能减少旅客的出行次数, 从而降 低城市间的相互作用强度, 进而带来负面的经济和 社会影响。但现阶段尚缺乏高铁建设带来负面影 响的研究。梳理文献可以发现, 国内外学者已从不 同的视角对时间价值、高速铁路建设所引致的时间 节约和票价提升进行了研究, 这为本文的“被高铁” 的测算提供了基础。

在时间价值的研究方面, Oort(1969)认为旅行 时间的减少通常是投资交通基础设施的重要结果,
以货币的形式对节省的旅行时间进行估计是决定 项目优劣的重要依据。DeSerpa(1971)认为效用函 数不应只是对商品的衡量,还应考虑时间因素, 而 个人的决定受到金钱和时间的共同约束,并在此假 设基础上建立了模型以研究时间的经济学意义。 赵延龙(1998)和刘东坡(2003)认为, 旅行过程中时 间的节约意味着可以将节约的时间用于其他生产 从而增加收人, 并对节约旅行时间价值的具体度量 方法进行了介绍。Mackie等(2003)提交给英国交通 部的研究报告中系统地对旅行节省的时间价值进 行了介绍。薛亮等(2009)通过对旅客选择运输方式 的属性因素和决策变量做了概述, 然后根据旅客出 行目的对旅客旅行时间价值的选择进行分类,计算 了不同交通方式的适用范围。

在高速铁路建设所引致的时间节约和票价提 升研究方面, 有学者认为, 高速铁路建设所带来的 最明显收益就是节省旅客的时间。但高铁的票价 对大多数旅客而言是很高的, 廉价且可满足基本舒 适条件的旅行对于一般的中国旅客更有意义。高 铁只能在拥有大量人口且高收人水平的区域才能 吸引足够多的旅客, 这样其所带来的收益才可覆盖 高铁的建设与运营所产生的成本。而节省的时间 价值与工资率、旅行成本和旅行时间的安排有关 (Zhao et al, 2013; Zhao et al, 2015)。王茜(2014)和 崔萌萌(2014)从不同的角度对高铁票价的定价机制 进行了研究, 认为高铁在定价时可实施灵活的票价 体系。Wu等(2014)提到铁路依然在客运和货运市 场发挥着重要的作用, 因此增加铁路的建设是必要 的。他们对建设新的高速铁路是否为解决铁路运 力问题的最有效途径进行了研究, 认为在当前中国 旅客整体上时间价值不高且差异很大的情况下, 新 建设更多的普通列车是解决中国铁路容量问题更 有效的方法。蒋海兵等(2015)从高铁与出行成本的 角度研究了旅行者的经济可达性空间格局, 认为在 当前全国的平均工资水平下,普通旅客的支付能力 较低, 以私人目的乘坐高铁的意愿不高。

虽然已有不少学者认识到了高铁的高票价会 对人们的出行(尤其是收人水平偏低的群体)带来影 响, 也指出了这一影响与个人的时间价值相关, 但 目前为止, 对 “被高铁”问题的讨论还只限于新闻媒 体, 还没有人对这些相关因素及其对人们出行的影 响进行过具体测算。本文在理性人的假设前提下， 依据货币与时间在人们出行决策中的替代关系, 以 
城市为单位, 基于普通收人群体, 分析了 “被高铁” 现象的可能性和程度, 为 “被高铁”现象的理性研究 提供了一个基本思路。

\section{2 方法与数据}

本文以京沪高铁沿线城市为样本, 并将研究范 围限定在这些城市的居民沿京沪高铁线的铁路出 行行为, 其出行时的交通选择只包括乘坐普通列车 或高铁。首先依据旅客列车时刻表计算由普通铁 路转乘高铁每节省单位时间需要付出的货币成本; 然后将此货币成本与沿线城市居民小时工资进行 比较, 判断哪些城市之间的旅行会 “被高铁”, 并计 算了沿线城市的“被高铁数”; 进一步结合高铁车次 比重得到“被高铁可能性”和“被高铁程度”。

\section{1 理论依据}

经济学中把时间看作是一种资源。每个人每 天都有 24 个小时的时间, 如何在不同的活动中分配 时间, 就成为一种基本的决策行为。理性人在进行 决策时, 目标是使自身的效用最大化(效用是对人 们满足感的衡量)。就时间这项资源的分配来说， 最简单的是在工作和休闲之间进行分配。工作时 间可以挣工资, 用于购买各种商品, 商品的消费带 来了效用; 休闲时间可以进行娱乐和休息, 也可以 带来效用。如果 1 小时用于工作带来的效用大于休 闲带来的效用, 就应该增加工作时间; 反过来如果 休闲时间的效用大于工作时间, 就应该增加休闲的 时间。根据经济学的边际效用递减规律, 随着时间 在某种活动中的增加, 单位时间带来的效用是递减 的, 所以总效用的最大化发生在工作时间的边际效 用与休闲时间的边际效用相等时。

将这一理论应用于出行决策的研究, 就可以对 “被高铁”现象进行一个理性分析。旅客的出行需 支付货币成本和时间成本。货币成本表现为旅客 乘坐交通工具所支付的费用, 时间成本是旅客乘坐 交通工具所消耗的时间。货币和时间都是人们掌 握的资源, 可以给人们带来效用; 而当有不同的交 通方式可供选择时, 货币和时间二者是可以相互替 代的。乘坐高铁, 可以节省时间, 但要付出较高的 货币成本; 乘坐普通列车, 所需时间较长, 但货币成 本较低。为把时间成本用价值量来衡量, 经济学家
常以“小时工资”作为 1 小时的价值。这样虽然每个 人每天都有 24 小时的时间, 但时间价值却有很大的 不同。时间价值高的人愿意多支付货币成本来节 省时间，而时间价值低的人愿意多花些时间来节省 货币,而人们的决策目标都是自身效用的最大化。 这样,通过计算由乘坐普通列车转向乘坐高铁每节 省单位时间所付出的货币成本, 再与小时工资(时 间价值)做比较, 就可以知道什么收人水平的人乘 坐高铁是合理(可提高其效用水平), 或不合理的。 而当后者不得不乘坐高铁时, 就是“被高铁”了。

\section{2 研究范围}

本文的研究对象是京沪高铁沿线的 23 个城市, 其中由于定远只有 $\mathrm{G}$ 字头高铁, 没有普通铁路, 无 法比较, 故将其舍去。其余共计 22 个城市(图 1), 相 互间构成 462 个“城市对”。由于去程和返程的铁路 票价和时间可认为是一样的,本文在测算时实际分 析了 231 个“城市对”的“被高铁”情况。

\section{3 小时工资的计算方法}

城市居民的工资数据来自各地 2013 年统计年 鉴,年鉴中的数据统计的是 2012 年的信息。由于计 算票价时采用的是列车时刻表 2015 年 1 月 1 日的数 据, 则各城市的小时工资也做相应的换算。根据国 家统计局的数据, 2012-2014年的城镇单位就业人 员平均工资分别为 $46769 、 51483 、 56339$ 元，而 2013 年和 2014 年的城镇单位就业人员平均工资增长率 分别为 $10.07 \%$ 和 $9.43 \%$, 即 2014 年的工资为 2012 年的 1.2046 倍。按此倍数将各城市小时工资调整 到2014年水平 ${ }^{(1)}$ 。

小时工资代表乘客的时间价值,计算中采用年 鉴中根据 2013 年与 2014 年增长率换算后的城镇居 民工资;一年工作时间以 250 天计算,一天计 $8 \mathrm{~h}$, 则 计算公式如下:

$$
\text { Wage }=\frac{\text { Income }}{250 \times 8}
$$

式中: Wage 指城镇居民小时工资; Income 指换算后 的城镇居民年工资。

\section{4 旅客节省的单位时间价值的计算方法}

本文采用的铁路时间、票价、车次等数据均来 自列车时刻表 2015 年 1 月 1 日的数据。把高铁 $(\mathrm{G}$ 字头列车)和动车 $(\mathrm{D}$ 字头列车)归为高铁类列车, 把 $\mathrm{T}$ (特快)、 $\mathrm{Z}$ (直达)、 $\mathrm{K}$ (快速) 和 $\mathrm{P}$ (普通车, 本文指无字 头普通列车, 如 1461)归为非高铁类列车。考虑到

(1)济宁市的情况比较特殊。济宁最大的普铁站是充州站(充州现为济宁的一个市辖区), 高铁站设在曲阜。因此, 本研究中将济宁作为研究城 市, 充州站视为济宁的普铁站, 曲阜东站视为济宁的高铁站。相应地, 工资采用济宁的数据。 


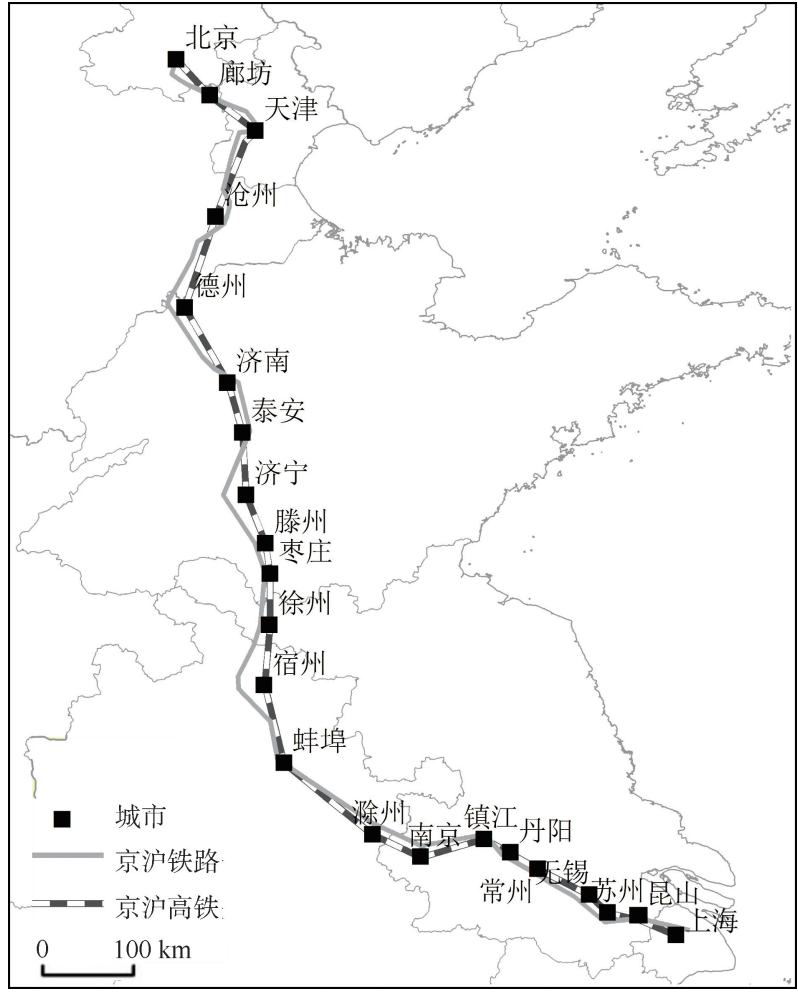

图 1 京沪高铁途径城市示意图

Fig.1 Beijing-Shanghai high-speed railway corridor

高铁类列车的一等座票价太高, 不具代表性, 因此 取高铁类列车的二等座票价与非高铁类列车的硬 卧与硬座作对比分析。同时, 若 “城市对”之间的运 行时间大于 $8 \mathrm{~h}$, 则对高铁类列车的二等座与非高 铁类硬卧对应进行分析; 若“城市对”之间的运行时 间小于 $8 \mathrm{~h}$, 则对高铁类列车二等座与非高铁类列 车硬座相对应进行分析。例如, 某 “城市对”间有 $G 、 D 、 T($ 包括 $Z$ )、 $K$ 和 $P 5$ 种车次, 则要计算乘客由 $T 、 K 、 P 3$ 种普铁转乘 $G$ 和 $D 2$ 种高铁共 6 种情况下 (T-G、K-G、P-G、T-D、K-D、P-D)时间节省的货币成 本, 然后再根据各类车次的频次, 将 6 个数值乘以相 应的频次权重并进行加和得出一个综合的时间节 省的货币成本数值, 此数值在数学上称为期望值。 时间节省的货币成本的计算是基于旅客的旅行时 间和旅行成本可以相互替代, 即是旅客出行的成本 差值与出行的时间差值的比值。

用公式表示计算过程如下:

$$
\begin{gathered}
v_{i j}^{\mathrm{TG}}=\frac{P_{i j}^{\mathrm{G}}-P_{i j}^{\mathrm{T}}}{t_{i j}^{\mathrm{T}}-t_{i j}^{\mathrm{G}}}, \\
v_{i j}^{\mathrm{KG}}=\frac{P_{i j}^{\mathrm{G}}-P_{i j}^{\mathrm{K}}}{t_{i j}^{\mathrm{K}}-t_{i j}^{\mathrm{G}}}, \cdots \cdots
\end{gathered}
$$

$$
\begin{gathered}
V_{i j}^{\mathrm{TG}}=\frac{n_{i j}^{\mathrm{T}}}{n_{i j}^{\mathrm{T}}+n_{i j}^{\mathrm{K}}+n_{i j}^{\mathrm{P}}} \times \frac{n_{i j}^{\mathrm{G}}}{n_{i j}^{\mathrm{G}}+n_{i j}^{\mathrm{D}}} \times \overline{v_{i j}^{\mathrm{TG}}}, \\
V_{i j}^{\mathrm{KG}}=\frac{n_{i j}^{\mathrm{K}}}{n_{i j}^{\mathrm{T}}+n_{i j}^{\mathrm{K}}+n_{i j}^{\mathrm{P}}} \times \frac{n_{i j}^{\mathrm{G}}}{n_{i j}^{\mathrm{G}}+n_{i j}^{\mathrm{D}}} \times \overline{v_{i j}^{\mathrm{KG}}}, \cdots \cdot . \\
E_{i j}=V_{i j}^{\mathrm{TG}}+V_{i j}^{\mathrm{KG}}+V_{i j}^{\mathrm{PG}}+V_{i j}^{\mathrm{TD}}+V_{i j}^{\mathrm{KD}}+V_{i j}^{\mathrm{PD}}
\end{gathered}
$$

式中: $i$ 指出发城市; $j$ 指到达城市; $n$ 指发车频次; $P_{i j}$ 指城市 $i$ 和城市 $j$ 间的列车票价; $t_{i j}$ 指城市 $i$ 和城市 $j$ 间的列车运行时间; $v_{i j}^{\mathrm{TG}}$ 指城市 $i$ 和城市 $j$ 间由 $\mathrm{T}$ 转 乘 $\mathrm{G}$ 节省的单位时间的货币成本; $\overline{v_{i j}^{\mathrm{TG}}}$ 指计算出的 所有 $v_{i j}^{\mathrm{TG}}$ 的平均值; $V_{i j}^{\mathrm{TG}}$ 指城市 $i$ 和城市 $j$ 间由 $\mathrm{T}$ 转 乘 $\mathrm{G}$ 的频次权重与节省的单位时间的货币成本的 乘积; $E_{i j}$ 指城市 $i$ 和城市 $j$ 间节省的单位时间的货币 成本。

根据前文的经济决策原理,当时间节省的货币 成本低于小时工资时,旅客出行乘坐高铁是合理 的, 因为把节省下来的时间用于工作可以带来更高 的收益; 若时间节省的货币成本高于小时工资,则 乘坐高铁就是不合理的,会使其总收益即总效用下 降。本文把后一种情况定义为“被高铁”。

由于本文的分析以城市为单位, 时间节省的货 币成本按“城市对”来计算，即 231 个“城市对”之间 各自时间节省的货币成本; 小时工资是各城市的平 均工资; 两者对比就可以找出“被高铁” 的“城市 对”。由于“城市对”中 2 个城市的平均工资是不同 的,而两城市之间时间节省的货币成本是同一个数 值,所以可能其中的一个城市会“被高铁”, 另一个 则不会。鉴于此,本文以城市为单位做了 3 种测算: 一是从某城市出发到其他 21 个城市的出行有多少 个城市会“被高铁”, 称为“被高铁数”; 二是由于各 城市之间还是有普通客运列车在运行, 旅客出行不 一定非得乘高铁, 所以计算了“被高铁”的可能性, 即某城市到其他 “被高铁”城市之间高铁车次占总 车次比重的均值; 三是综合以上 2 种计算,测量出各 城市的“被高铁程度”,即“被高铁数”乘以“被高铁 可能性”后除以可比城市数(数值为 21), 用于对比各 城市受“被高铁”影响的程度。

\section{3 时间节省的货币成本和小时工资}

\section{1 京沪高铁沿线“城市对”时间节省的货币成本}

根据前文所述测算方法, 对京沪高铁沿线各 “城市对”的单位时间的货币成本进行测算。由于 城市数量众多, 限于篇幅, 不能对每个城市进行详 
细分析。因此, 按照城市人口规模, 并考虑城市的 代表性, 选取北京、德州和丹阳 3 个城市进行详细 分析。

从表 1 可以看出, 北京到其他城市单位时间节 省的货币成本最大值、最小值分别出现在北京一徐 州(38.38)、北京一济宁(13.95); 从北京到其他城市 单位时间节省的货币成本的平均值为 23.50 。从表 2 可以看出, 德州到其他城市单位时间节省的货币 成本最大值、最小值分别出现在德州一蚌埠 (32.52)、德州一滁州(18.48); 从德州到其他城市单 位时间节省的货币成本的平均值是 25.56 。从表 3 可以看出, 丹阳到其他城市单位时间节省的货币成 本最大值、最小值分别出现在丹阳一南京(54.78)、 丹阳一镇江(3.89); 从丹阳到其他城市单位时间节 省的货币成本的平均值是 30.03 。

对比 3 个城市到其他城市单位时间节省的货币 成本的平均值发现, 北京的单位时间节省的货币成 本的平均值较低, 而丹阳的单位时间节省的货币成 本的平均值较高。不同城市的单位时间节省的货 币成本的数值有较大差异。

另外的 19 个城市, 每个城市都进行了同样的计 算, 得到每个城市到其他 21 个城市单位时间节省的 货币成本(表略)。

\section{2 京沪高铁沿线城市城镇居民小时工资}

根据前文所述的测算方法, 得出各城市 2014 年 的小时工资如表 4 所示。

从表 4 可以看出, 小时工资最高的是北京, 达 51.38 元; 小时工资最低的是德州, 仅为 20.27 元。 总的来看, 直辖市、经济发达省份的省会城市以及 长三角一带的城市城镇居民的小时工资高; 而河 北、山东和安徽的一些城市小时工资较低。

\section{3 时间节省的货币成本与小时工资的比较}

以下以北京、德州、丹阳为例说明时间节省的 货币成本与小时工资比较的结果。

从图 2 可以看出, 北京的小时工资为 51.38 元; 北京到其他城市时间节省的货币成本最大值出现 在北京到徐州, 为 38.38 。可见所有 “城市对”间时 间节省的货币成本均小于北京的小时工资, 所以对 北京的城镇居民而言, 不存在“被高铁”现象。

从图 3 可以看出, 德州城镇居民的小时工资为 20.27 元; 德州到其他城市时间节省的货币成本最 大值出现在德州到蚌埠, 为 32.52 ; 最小值出现在德 州到滁州, 为 18.48 。有 19 个城市时间节省的货币
成本高于德州城镇居民的小时工资, 则去往这 19 个 城市的旅客出行会 “被高铁”, 只有去往昆山、溆州 这 2 个城市的旅客不会“被高铁”。

从图 4 可以看出, 丹阳城镇居民的小时工资为 27.30 元; 丹阳到其他城市时间节省的货币成本最 大值出现在丹阳到南京, 为 54.78 ; 最小值出现在丹 阳到镇江, 为 3.89 。有 14 个城市的货币成本高于丹 阳城镇居民的小时工资, 则去往这 14 个城市的旅客 出行会被“被高铁”。

\section{表 1 北京到其他城市通过乘坐高铁 每节省 1 小时需付出的货币成本}

Tab.1 The monetary cost passengers pay to save one hour by taking high-speed railway from Beijing to other cities

\begin{tabular}{cc||cc||cc||cc}
\hline 城市 & $\begin{array}{c}\text { 时间 } \\
\text { 价值 }\end{array}$ & 城市 & $\begin{array}{r}\text { 时间 } \\
\text { 价值 }\end{array}$ & 城市 & $\begin{array}{r}\text { 时间 } \\
\text { 价值 }\end{array}$ & 城市 & $\begin{array}{r}\text { 时间 } \\
\text { 价值 }\end{array}$ \\
\hline 廊坊 & 31.47 & 济宁 & 13.95 & 滁州 & 18.42 & 苏州 & 21.86 \\
天津 & 32.03 & 滕州 & 16.62 & 南京 & 21.44 & 昆山 & 18.72 \\
沧州 & 28.65 & 余庄 & 16.61 & 镇江 & 21.80 & 上海 & 20.47 \\
德州 & 30.31 & 徐州 & 38.38 & 丹阳 & 19.75 & & \\
济南 & 24.88 & 宿州 & 22.42 & 常州 & 20.69 & & \\
泰安 & 30.33 & 蚌埠 & 22.55 & 无锡 & 22.08 & & \\
\hline
\end{tabular}

\section{表 2 德州到其他城市通过乘坐高铁}

每节省 1 小时需付出的货币成本

Tab.2 The monetary cost passengers pay to save one hour by taking high-speed railway from Dezhou to other cities

\begin{tabular}{cc||cc||cc||cc}
\hline 城市 & $\begin{array}{c}\text { 时间 } \\
\text { 价值 }\end{array}$ & 城市 & $\begin{array}{c}\text { 时间 } \\
\text { 价值 }\end{array}$ & 城市 & $\begin{array}{c}\text { 时间 } \\
\text { 价值 }\end{array}$ & 城市 & $\begin{array}{c}\text { 时间 } \\
\text { 价值 }\end{array}$ \\
\hline 北京 & 30.31 & 济宁 & 23.46 & 滁州 & 18.48 & 苏州 & 24.23 \\
廊坊 & 23.08 & 滕州 & 28.79 & 南京 & 21.07 & 昆山 & 20.24 \\
天津 & 27.99 & 余庄 & 27.35 & 镇江 & 25.52 & 上海 & 24.51 \\
沧州 & 29.17 & 徐州 & 31.12 & 丹阳 & 21.09 & & \\
济南 & 20.55 & 宿州 & 30.90 & 常州 & 23.72 & & \\
泰安 & 27.63 & 蚌埠 & 32.52 & 无锡 & 25.09 & & \\
\hline
\end{tabular}

\section{表 3 丹阳到其他城市通过乘坐高铁 \\ 每节省 1 小时需付出的货币成本}

Tab.3 The monetary cost passengers pay to save one hour by taking high-speed railway from Danyang to other cities

\begin{tabular}{|c|c|c|c|c|c|c|c|}
\hline 城市 & $\begin{array}{l}\text { 时间 } \\
\text { 价值 }\end{array}$ & 城市 & $\begin{array}{l}\text { 时间 } \\
\text { 价值 }\end{array}$ & 城市 & $\begin{array}{l}\text { 时间 } \\
\text { 价值 }\end{array}$ & 城市 & $\begin{array}{l}\text { 时间 } \\
\text { 价值 }\end{array}$ \\
\hline 北京 & 19.75 & 泰安 & 34.68 & 蚌埠 & 34.03 & 苏州 & 40.16 \\
\hline 廊坊 & 20.52 & 济宁 & 30.72 & 滁州 & 32.37 & 昆山 & 35.97 \\
\hline 天津 & 21.04 & 滕州 & 31.61 & 南京 & 54.78 & 上海 & 30.48 \\
\hline 沧州 & 21.32 & 菄庄 & 33.53 & 镇江 & 3.89 & & \\
\hline 德州 & 21.09 & 徐州 & 34.02 & 常州 & 28.08 & & \\
\hline 济南 & 23.14 & 宿州 & 29.81 & 无锡 & 49.73 & & \\
\hline
\end{tabular}




\section{4 “被高铁”的测算与影响因素分析}

\section{1 “被高铁”的测算}

本小节对京沪高铁沿线城市的“被高铁数” “被高铁可能性”和“被高铁程度”进行了测算。

\subsection{1 京沪高铁沿线城市“被高铁数”的测算}

通过对城市城镇居民的小时工资与该城市到 其他城市节省的单位时间的货币成本进行比较, 将 “被高铁数”从小到大排列, 统计结果如下表所示:

从表 5 可以看出, 由于北京和上海的高收人, 这 两个城市均不存在 “被高铁” 的现象。天津只到沧 州“被高铁”, 这是由于两城市之间距离较短, 高铁 的时间优势体现不出来, 票价差别又很大造成的。 “被高铁数” 在 4 8 个的城市都是省会以及长三角地 区的城市, “被高铁数” 为 12 19 个的城市多在安徽 和山东两省, 相比之下这些城市的经济欠发达, 城 镇居民出行更有可能承受较高的成本。而对于德 州的旅客而言, 仅去昆山、滁州这两个城市不会“被 高铁”。

\subsection{2 京沪高铁沿线城市“被高铁可能性”的测算}

对前文定义的“被高铁可能性”进行计算, 以 “被高铁数”从小到大排列的各个城市的“被高铁可

表 4 各城市的小时工资

Tab.4 Hourly wage of each city

\begin{tabular}{cc||cc||cc||cc}
\hline 城市 & $\begin{array}{c}\text { 小时工 } \\
\text { 资/元 }\end{array}$ & 城市 & $\begin{array}{c}\text { 小时工 } \\
\text { 资/元 }\end{array}$ & 城市 & $\begin{array}{c}\text { 小时工 } \\
\text { 资/元 }\end{array}$ & 城市 & $\begin{array}{c}\text { 小时工 } \\
\text { 资/元 }\end{array}$ \\
\hline 北京 & 51.38 & 泰安 & 24.08 & 蚌埠 & 22.92 & 无锡 & 34.26 \\
廊坊 & 27.36 & 济宁 & 26.71 & 滁州 & 25.20 & 苏州 & 34.71 \\
天津 & 37.48 & 滕州 & 20.90 & 南京 & 36.38 & 昆山 & 32.20 \\
沧州 & 24.16 & 菄庄 & 23.48 & 镇江 & 28.69 & 上海 & 48.30 \\
德州 & 20.27 & 徐州 & 26.54 & 丹阳 & 27.30 & & \\
济南 & 29.41 & 宿州 & 21.90 & 常州 & 33.59 & & \\
\hline
\end{tabular}

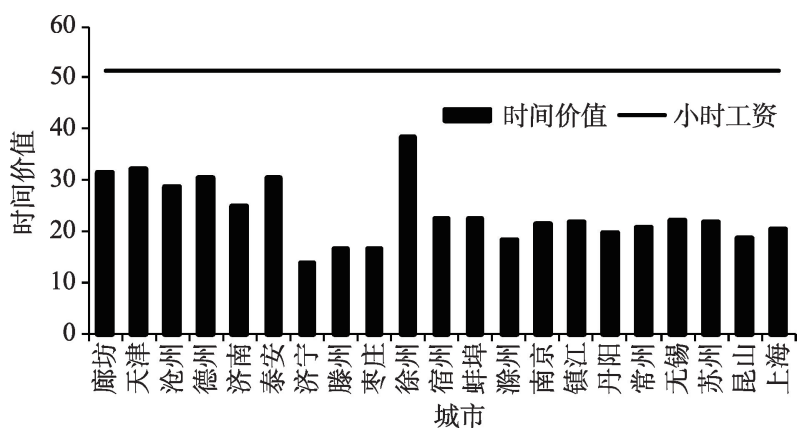

图 2 北京的小时工资与到其他城市时间节省的 货币成本的比较

Fig.2 Comparison of Beijing's hourly wage with the monetary cost from Beijing to other cities
能性”如下:

由表 6 可以看出,由于北京和上海不存在“被高 铁”, 因此在计算 “被高铁可能性”时空缺。其他城 市中, “被高铁可能性”最大的是昆山 0.74 ,最小的 是蛙埠 0.32 。各城市的“被高铁可能性”平均值是 0.52。“被高铁可能性”越大的城市，由于“城市对”间 高铁类列车的比重较高, 则旅客支付更高成本的可 能性也就越大。

\subsection{3 京沪高铁沿线城市 “被高铁程度”的测算}

为对比各城市受 “被高铁”影响的程度,将“被 高铁数”乘以“被高铁可能性”, 再除以可比城市数 (数值为 21), 并将其以柱状图形式在京沪高铁途径 城市示意图中标注(图 5)。从图 5 可以看出, 以城市 为单位, 以京沪高铁为研究对象,各城市的“被高铁 程度”整体呈现出 “两头低, 中段高, 长三角相对较 低”的特征。由于北京、上海的高工资,两市的旅客 出行不会“被高铁”, 因此“被高铁程度”最低; 而位 于靠近端点位置的廊坊, 其“被高铁程度”也很低, 为 0.07 ; 而德州为最高, 达 0.50 , 主要是由于德州的 “被高铁城市数”高达 19 ,另外, 德州的“被高铁可能

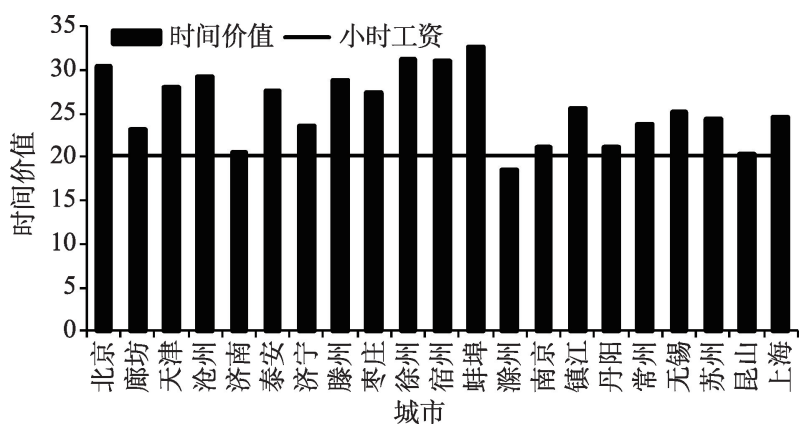

图 3 德州的小时工资与到其他城市时间节省的 货币成本的比较

Fig.3 Comparison of Dezhou's hourly wage with the monetary cost from Dezhou to other cities

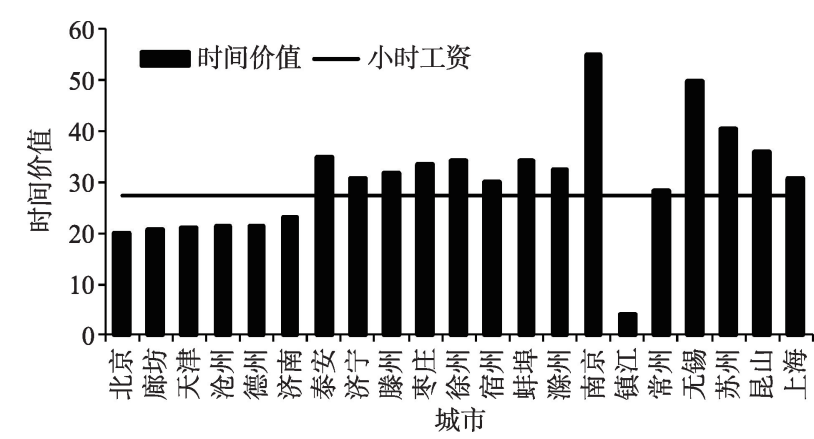

图 4 丹阳的小时工资与到其他城市时间节省的 货币成本的比较

Fig.4 Comparison of Danyang's hourly wage with the monetary cost from Danyang to other cities 
性”为 0.56 , 也高于平均值 0.52 ; 而靠近上海的昆山 为 0.18 , 低于平均值 0.24 。

整体来看, 经济发达的城市如直辖市北京、上 海、天津, 省会城市济南、经济发达城市苏州、昆山 等“被高铁程度”较低; 而位于中部省份的城市, 如 山东的德州、泰安, 安徽的宿州等, 其经济相对不够 发达,则“被高铁程度”较高; 而省会南京城市, 虽然 其“被高铁数”是 8 并不高, 但是其“被高铁可能性” 达 0.71 , 因此“被高铁程度”也达 0.27 , 介于蚌埠和镇 江之间; 而济南虽然 “被高铁可能性”为 0.68 , 但其 “被高铁数”仅有 4 , 因此其“被高铁程度”也很低。

\section{2 “被高铁”的影响因素分析}

影响 “被高铁” 的因素包括高铁类列车和非高 铁类列车的票价与运行时间、发车频次以及居民工 资水平。

票价与运行时间因素, 对于非高铁类列车中 $\mathrm{T}$ (包括 Z) 字头车相对更多的城市, 由于 $\mathrm{T}$ (包括 Z) 字 头车和高铁间的时间差较小, 因此单位时间节省的 货币成本相应地更高,这会增加这些城市的“被高 铁数”, 进而提升 “被高铁程度”; 而对于非高铁类列 车中无字头列车相对更多的城市, 由于无字头列车 和高铁间的时间差很大，因此单位时间节省的货币

表 5 各城市的“被高铁数”

Tab.5 Number of "involuntary high-speed railway travel” destinations of each city

\begin{tabular}{cc||cc||cc||cc}
\hline 城市 & $\begin{array}{c}\text { 被高铁 } \\
\text { 数/个 }\end{array}$ & 城市 & $\begin{array}{c}\text { 被高铁 } \\
\text { 数/个 }\end{array}$ & 城市 & $\begin{array}{c}\text { 被高铁 } \\
\text { 数/个 }\end{array}$ & 城市 & $\begin{array}{c}\text { 被高铁 } \\
\text { 数/个 }\end{array}$ \\
\hline 北京 & 0 & 苏州 & 6 & 镇江 & 13 & 泰安 & 18 \\
上海 & 0 & 南京 & 8 & 滁州 & 14 & 宿州 & 18 \\
天津 & 1 & 常州 & 8 & 丹阳 & 14 & 滕州 & 19 \\
廊坊 & 2 & 无锡 & 8 & 徐州 & 16 & 德州 & 19 \\
济南 & 4 & 沧州 & 11 & 查庄 & 16 & & \\
昆山 & 5 & 济宁 & 12 & 蚌埠 & 18 & & \\
\hline
\end{tabular}

表 6 各城市的“被高铁可能性”

Tab.6 Possibility of "involuntary high-speed railway travel” of each city

\begin{tabular}{cc||cc||cc||cc}
\hline 城市 & $\begin{array}{c}\text { 被高铁 } \\
\text { 可能性 }\end{array}$ & 城市 & $\begin{array}{c}\text { 被高铁 } \\
\text { 可能性 }\end{array}$ & 城市 & $\begin{array}{c}\text { 被高铁 } \\
\text { 可能性 }\end{array}$ & 城市 & $\begin{array}{c}\text { 被高铁 } \\
\text { 可能性 }\end{array}$ \\
\hline 北京 & - & 苏州 & 0.60 & 镇江 & 0.50 & 泰安 & 0.44 \\
上海 & - & 南京 & 0.71 & 滁州 & 0.33 & 宿州 & 0.38 \\
天津 & 0.43 & 常州 & 0.55 & 丹阳 & 0.50 & 滕州 & 0.47 \\
廊坊 & 0.70 & 无锡 & 0.54 & 徐州 & 0.54 & 德州 & 0.56 \\
济南 & 0.68 & 沧州 & 0.48 & 杳庄 & 0.43 & & \\
昆山 & 0.74 & 济宁 & 0.43 & 蚌埠 & 0.32 & & \\
\hline
\end{tabular}

成本相应地较低,会降低这些城市的“被高铁数”, 进而减少“被高铁程度”。而 $\mathrm{T}$ (包括 Z) 字头车更多 地停靠在大城市, 所以从票价与运行时间因素分 析,大城市的“被高铁程度”会相对较高。

发车频次因素, 决定了“被高铁可能性”的大 小。对于那些“被高铁”的城市, 若非高铁类列车发 车频次较多,那么“被高铁可能性”相应地更小。但 是, 若进一步减少非高铁类列车发车频次, 那么会 增加这些城市的“被高铁可能性”, 进而提升 “被高 铁程度”。而对于非高铁类列车, 如果进一步减少 其中的无字头列车发车频次, 则会增大单位时间节 省的货币成本,进而提升“被高铁程度”。

旅客的工资水平, 是影响“被高铁程度”的最直 接因素。因此, 即使 $\mathrm{T}$ (包括 Z) 字头车更多停靠在大 城市, 但是大城市平均工资水平明显较高, 所以对 京沪沿线的大城市而言, “被高铁程度”并不突出; 对于京沪高铁沿线的小城市, 虽然非高铁类列车中 $\mathrm{T}$ (包括 Z) 字头车比重不高, 但这些城市平均工资水 平明显较低,因而其“被高铁程度”仍然很高。

由以上分析可以看出, 收人与 “被高铁程度”成 负相关关系, 即收人越高, “被高铁程度”越低; 普铁 列车车次与 “被高铁程度”也成负相关关系, 即普铁

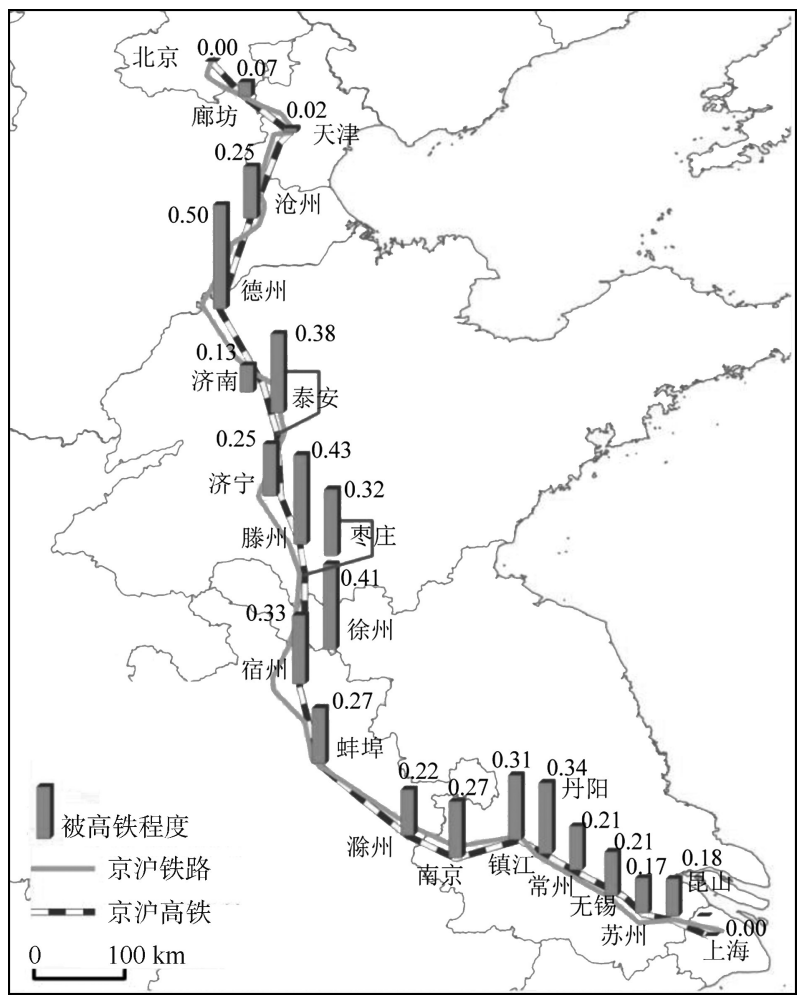

图 5 “被高铁程度”示意图

Fig.5 Extent of “involuntary high-speed railway travel” 
列车车次越多, “被高铁程度”越低; 而高铁车次和 高铁票价与 “被高铁程度” 成正相关关系, 即高铁车 次越多、票价越高, 则 “被高铁程度”越高。若保持 铁路车次和票价不变, 随着城市居民收人的上升, “被高铁程度” 会逐步降低; 但如果为了提高货运运 力而减少较多的普铁车次, 则会引起 “被高铁程度” 的上升。所以普铁车次的调整应考虑到收人的上 升速度, 利用二者之间的对应关系, 将 “被高铁程 度”控制在公众可接受的水平上。

\section{5 结论}

本文在基于时间节省的货币成本与各地工资 水平计算的基础上, 通过对比研究分析了各城市到 其他城市 “被高铁” 的数量、可能性与程度, 主要结 论有:

(1) “被高铁” 具有普遍性。由于不同城市的小 时工资相差较大, 总的来看, 直辖市、经济发达省份 的省会城市以及长三角一带的城市城镇居民的小 时工资高; 而河北、山东和安徽的一些城市的小时 工资较低。城镇居民的小时工资水平是影响城市 “被高铁数”的最直接因素。北京、上海等经济发达 城市的“被高铁数”最低, 德州、滕州、泰安的“被高 铁数”很高。

(2) “被高铁” 的可能性在 50\%左右。各城市的 “被高铁可能性”平均值是 0.52 , 说明整体来看, 旅 客出行有较大的可能性会选择高铁。“被高铁可能 性”越大的城市, 由于 “城市对”间高铁类列车的比 重较高, 则旅客支付更高成本的可能性也就越大。

(3) 各城市 “被高铁” 的程度有较大差异。京沪 高铁沿线城市的“被高铁程度”整体呈现出 “两头 低、中段高、长三角相对较低” 的特征。经济发达的 城市如直辖市北京、上海、天津很低; 而位于线路中 部省份的城市, 如山东的德州、滕州、安徽的宿州 等, 其经济相对不够发达, 则 “被高铁程度”较高。 长三角地区经济发达城市如苏州、昆山等“被高铁 程度”较低。

中国高铁建设的重要目的之一是客货分流, 即 减少或逐步取消普铁客运列车, 将普通铁路用于货 运。但普铁客运的减少必然会带来 “被高铁” 情况 的发生, 需要在提高铁路利用效率和保障公民出行 之间进行权衡, 将 “被高铁程度”控制在公众可以接 受的程度之内。根据本文的分析, 收人的提高可以
降低 “被高铁程度”,而普铁车次的减少会提高“被 高铁程度”, 下一步可对二者间相互作用关系作更 深人的研究。因此, 随着人们收人水平的提高, 铁 路部门可以测算出在不加重“被高铁程度”的前提 下,通过减少普铁车次, 从而将“被高铁程度”控制 在合理的水平上。

未来进一步地分析还应考虑更多的影响因素， 如单位距离票价随距离的增加而递减、白天与夜晚 时间价值的不同、各城市内部不同行业收人水平的 差异等,这些因素是下一步要深化分析的方向。

\section{参考文献(References)}

褚楠楠. 2013. 我国高速铁路成本效益研究[D]. 石家庄: 石家 庄铁道大学. [Chu N N. 2013. Research on cost and benefit of high-speed-railway in China[D]. Shijiazhuang, China: Shijiazhuang Tiedao University.]

崔萌萌. 2014. 我国高速铁路运价形成机制研究[D]. 北京: 北 京交通大学. [Cui M M. 2014. Research on price forming mechanism of HSR in China[D]. Beijing, China: Beijing Jiaotong University.]

海晓伟. 2014. 客运专线运力资源优化配置研究[D]. 北京: 北 京交通大学. [Hai X W. 2014. Transport capacity resources optimizing allocation of passenger dedicated line[D]. Beijing, China: Beijing Jiaotong University.]

蒋海兵, 张文忠, 祁毅, 等. 2015. 高速铁路与出行成本影响 下的全国陆路可达性分析 [J]. 地理研究, 34(6): 10151028. [Jiang H B, Zhang W Z, Qi Y, et al. 2015. The land accessibility influenced by China's high-speed rail network and travel cost[J]. Geographical Research, 34(6): 1015-1028.]

刘东坡. 2003. 旅客旅行时间价值分析方法研究 [J]. 华东经 济管理, 17(4): 155-156. [Liu D P. 2003. Research on the approach to the travel time value analysis[J]. East China Economic Management, 17(4): 155-156.]

马崇岩. 2014. 高速铁路运输成本问题研究: 以京沈高速铁 路为例 [D]. 成都: 西南交通大学. [Ma C Y. 2014. Research on high speed railway's transportation cost: Based on Beijing-Shenyang passenger dedicated line[D]. Cheng$\mathrm{du}$, China: Southwest Jiaotong University.]

王茜. 2014. 基于成本和时间价值的高铁客运票价制定机理 研究[D]. 北京: 北京交通大学. [Wang Q. 2014. The pricing mechanism of high-speed passenger railway based on cost and time value[D]. Beijing, China: Beijing Jiaotong University.]

薛亮, 谢金宝, 刘小玲. 2009. 从旅客时间价值角度分析主要 交通方式的选择 [J]. 铁道运营技术, 15(1): 30-33, 36 . [Xue L, Xie J B, Liu X L. 2009. Cong lvke shijian jiazhi jiaodu fenxi zhuyao jiaotong fangshi de xuanze[J]. Rail- 
way Operation Technology, 15(1): 30-33, 36.]

杨维风, 张志军. 2009. 京沪高速铁路定价问题研究 [J]. 中国 物价, (2): 10-12. [Yang W F, Zhang Z J. 2009. Jinghu gaosu tielu dingjia wenti yanjiu[J]. China Price, (2): 1012.]

张萌萌, 孟晓晨. 2014. 高速铁路对中国城市市场潜力的影 响: 基于铁路客运可达性的分析 [J]. 地理科学进展, 33 (12): 1650-1658. [Zhang M M, Meng X C. 2014. Impact of high-speed railway on market potential of Chinese cities: Analyses based on railway passenger transport accessibility[J]. Progress in Geography, 33(12): 1650-1658.]

赵延龙, 刘振奎. 1998. 铁路旅客旅行时间价值分析方法 [J]. 兰州铁道学院学报, 17(4): 26-30. [Zhao Y L, Liu Z K. 1998. Analytical methods of the time value in railway passenger transport[J]. Journal of Lanzhou Railway Institute, 17(4): 26-30.]

DeSerpa A C. 1971. A theory of the economics of time[J]. The Economic Journal, 81: 828-846.

Mackie P J, Wardman M, Fowkes A S, et al. 2003. Values of travel time savings in the UK[R/OL]. Universities of Leeds: White Rose Research Online, 2013-02 [2016-0227]. http://eprints.whiterose.ac.uk/2079/.

Monzón A, Ortega E, López E. 2013. Efficiency and spatial equity impacts of high-speed rail extensions in urban areas [J]. Cities, 30: 18-30.

Oort C J. 1969. The evaluation of travelling time[J]. Journal of Transport, Economics and Policy, 3(3): 279-286.

Wu J H, Nash C, Wang D. 2014. Is high speed rail an appropriate solution to China's rail capacity problems[J]. Journal of Transport Geography, 40: 100-111.

Zhao J, Zhao Y Y. 2013. The value of travel time savings and the high speed rail in China[R/OL]. 2013-07-18 [2016-0227]. http://www.wctrs- society.com/wp/wp- content/uploads/abstracts/rio/selected/2559.pdf.

Zhao J, Zhao Y Y, Li Y. 2015. The variation in the value of travel-time savings and the dilemma of high-speed rail in China[J]. Transportation Research Part A: Policy and Practice, 82(5): 130-140.

\title{
"Involuntary high-speed railway travel": A case study based on the Beijing-Shanghai high-speed railway
}

\author{
ZHANG Kaiyang, MENG Xiaochen* \\ (College of Urban and Environmental Sciences, Peking University, Beijing 100871, China)
}

\begin{abstract}
Chinese high-speed railway entered a rapid development phase in recent years. One of the most important purposes of the construction of high- speed railway is to realize passenger and freight transport distributary. The construction of passenger train-dedicated high-speed railway has increased passenger transport capacity, thus releasing traditional train transport capacity for the usage of freight transport. But high-speed railway has higher ticket prices than traditional trains and the number of traditional trains in some cities has decreased, so people maybe have to pay much higher fare to take high-speed trains when traveling by railway. This phenomenon is called "involuntary high-speed railway travel". In this article, we analyze this phenomenon based on the Beijing-Shanghai high-speed railway by comparing the monetary cost computed using the 2015 train timetable with hourly wage, and then estimate the possibility of "involuntary high-speed railway travel" of each city. The result shows that: (1) "involuntary high-speed railway travel” exists in many cities as monetary cost exceeds hourly wage in these cities; (2) the possibility of "involuntary high-speed railway travel" is around $50 \%$; (3) the extent of "involuntary high-speed railway travel" varies in different cities-low at the endpoints, high in the middle, and relatively low in the Yangtze River Delta along the Beijing-Shanghai high-speed railway lines. Although traditional trains had not reduced too much along the Beijing-Shanghai high-speed railway lines, many low-income passengers may be forced to choose the high-speed railway once the number of traditional trains significantly declines, which may cause negative social impacts. This study can provide some references for the adjustment of the frequency of trains.
\end{abstract}

Key words: involuntary high-speed railway travel; monetary value of time; hourly wage; Beijing-Shanghai highspeed railway 